\title{
Integrated science and art education for creative climate change communication
}

\author{
$\underline{\text { Susan K. Jacobson }}^{1}, \underline{\text { Jennifer R. Seavey }}^{2,3,4}$ and Robert C. Mueller $^{5}$
}

\begin{abstract}
An interdisciplinary field trip to a remote marine lab joined graduate students from fine arts and natural resource science departments to think creatively about the topic of climate change and science communication. We followed a learning cycle framework to allow the students to explore marine ecosystems and participate in scientific lectures, group discussions, and an artist-led project making abstract collages representing climate change processes. Students subsequently worked in small groups to develop environmental communication material for public visitors. We assessed the learning activity and the communication product using pre- and post-field trip participant surveys, focus group discussions, and critiques by art and communication experts of the products. Significant changes in knowledge about climate change occurred in program participants. Incorporating artists and the arts into this activity helped engage multiple senses and emphasized social interaction, as well as providing support to participants to think creatively. The production of art helped to encourage peer learning and normalize the different views among participants in communicating about climate change impacts. Students created effective communication products based on external reviews. Disciplinary differences in cultures, language, and standards challenged participating faculty, yet unanticipated outcomes such as potentially transformative learning and improved teacher evaluations resulted.
\end{abstract}

Key Words: collage, creativity, education, environment, field trip, interpretation, peer learning, survey

\section{INTRODUCTION}

University programs in natural resource management focus on interventions to sustainably manage wildlife, fisheries, and forests. Topics such as climate change are framed as environmental problems; risks and impacts to the natural world are emphasized; and technical and technological solutions are sought (Jacobson et al. 2012). Only recently have courses begun incorporating concepts from the social sciences (Kareiva and Marvier 2012), and few integrate practices or paradigms from the arts and humanities to help students understand the broader context of individual and collective actions regarding the environment (Jacobson et al. 2007). However, different perspectives and ways of knowing the world can help students and researchers more holistically explore the problems and think more creatively about solutions. E. O. Wilson (Wilson 1998:8) proposed that consilience, the "jumping together of knowledge," and especially the "attempted linkage of the sciences and the humanities" will lead to great intellectual advancement. However, teaching materials often emphasize solely a science-based understanding of topics, while other ways of knowing are overlooked (Turner and Freedman 2004, Scheffer et al. 2015). This technocentric teaching approach often does not engage people in reflecting upon their values or behaviors, or offer opportunities for integrating this new awareness or different perspectives into the development of new and more effective solutions.

Climate change science remains controversial despite consensus in the scientific community, suggesting that more creative teaching and communication approaches are needed (Donner 2011, Jacobson et al. 2012). Environmental education and outreach ideally promote interdisciplinary understanding of the natural and built environment through the sciences, arts, and humanities. Art education about ecology "examines the interdependence of all living organisms within particular environments through interdisciplinary approaches to curriculum" (Stankiewicz and Krug 1997:4). Miles (2010) speculates that contemporary art dealing with climate change has a capacity to contribute to a shift in consciousness and likely to be conducive to a more sustainable way of living. Although science may be viewed as a process of discovery, the arts serve as another mode to acquire and interpret knowledge of the world. Different perspectives can help people realize that we are all engaged in a search for understanding the world around us. Interdisciplinary programs can help learners appreciate and engage in the wonders and rigor that science reveals to the artist, and the philosophical and creative context that the arts provide for science (Rous 2000, Jacobson et al. 2015). Scheffer et al. (2015) suggest that a greater alliance with artists and integration with art education could help catalyze scientific innovation by enhancing associative and divergent thinking in science students to complement systematic reasoning processes.

Researchers have found that using multiple ways to teach enhances learning (Weiss 2000, Benuš 2010). Activities such as art, music, poetry, and creative writing offer opportunities to address students' attitudes, beliefs, and emotions (Gurevitz 2000, Jacobson 2009), as well as providing a means to stimulate innovation (Kleiman 2011, Gurnon et al. 2013). Environmental art includes a range of practices that describe or celebrate nature, as well as ecological or politically motivated work that addresses environmental issues. Environmental art programs are often experiential as well as interdisciplinary. Exploration, observation, reading, writing, environmental monitoring, and problemsolving activities embedded in environmental art projects can help make topics relevant to learners and can improve creative problem-solving skills (DeHaan 2011, Jacobson et al. 2015). Incorporating art into the classroom can engage students who may not otherwise excel in academic settings, or can reveal students' hidden talents (Ford Foundation 2005).

\footnotetext{
${ }^{1}$ Department of Wildlife Ecology and Conservation, University of Florida, ${ }^{2}$ Shoals Marine Laboratory, ${ }^{3}$ School of Marine Science and Ocean Engineering, University of New Hampshire, ${ }^{4}$ College of Agriculture and Life Science, Cornell University, ${ }^{5}$ School of Art and Art History, University of Florida
} 
At the university level, few classes include art and biology to explore complex environmental problems. The use of the arts in climate change curricula is little mentioned in current examples of interdisciplinary education about climate change found on popular Internet sites, such as CAMEL (an interdisciplinary, multimedia resource for educators to teach about climate change, http://www.camelclimatechange.org), the National Oceanic and Atomspheric Administration (NOAA) Climate Education resources site (promoted to improve climate literacy and to "inform personal decisions about actions that influence climate," http://www.education.noaa.gov/Climate/), or the NASA Earth Systems, Technology, and Energy Education for MUREP(NASA ESTEEM)) website (http://esteem.larc.nasa.gov/) (Jacobson et al. 2012). These curricula emphasize core natural and physical science disciplines, yet single-discipline skill sets do not adequately prepare students with creative thinking or communication skills (Jacobson and McDuff 1998, Muir and Schwartz 2009, DeHaan 2011). Given severe and irreversible impacts expected from climate change in the coming decades (e.g., IPCC 2014), new approaches to education and training are needed to promote creative problem solving.

In this article, we describe the infusion of art-making into a graduate natural resource management course. We outline the pedagogical format and topical content of a class field trip module on climate change that combined advanced art and science students for an integrated learning experience. We followed a comprehensive model of learning developed by Danish psychologist and educator Knud Illeris (2003) that engages learners in an experience, helps them process and apply information in a new situation, and helps them share the experience by working in cooperative groups, thus incorporating an approach that includes environmental interaction, cognitive learning, and emotional learning (Jacobson et al. 2015). We describe our activities following the 5E learning cycle often used to teach science inquiry (Bybee et al. 2006). The learning cycle offers a general model to guide educators in designing a handson, experiential learning environment in which students are provided with an active experience and also with the opportunity for reflection on and analysis of that experience, hence the 5Es: engage, explore, explain, elaborate, and evaluate.

The goal of this case study was to explore the efficacy of an interdisciplinary learning experience integrating science and art students to enhance the curriculum of climate change and potentially other sustainability challenges. We used a field trip to a remote marine field laboratory to bring together art and natural resource graduate students with the following learning objectives:

1. Increase their understanding of the impacts of climate change to the Florida coast,

2. Gain exposure to new ways of viewing and interpreting the environment, including an art-making exercise to promote creative thinking, and

3. Explore effective communication techniques by developing material about the coastal environment for the lay public.

We used quantitative and qualitative evaluation methods to assess impacts of the integrated field trip (Jacobson 2009).

\section{METHODS}

\section{Study site}

The University of Florida Seahorse Key Marine Laboratory (Marine Lab) is located on a 66-ha island located in Levy County, Florida, part of the Cedar Keys National Wildlife Refuge (latitude: 29.096483, longitude: -83.06533). The island has a rich human history and a historical lighthouse serves as the base for the Marine Lab, which is leased by the University of Florida. The location of Seahorse Key provides access to diverse habitats including extensive marine grasses and algae, sandy beaches, mangroves, sand and mud flats, oyster bars, and salt marshes.

\section{Participants}

The study involved two artists, two biological scientists, and two courses with nine students from an advanced fine arts class and nine from a natural resource management class.

\section{Student learning}

The students participated in an orientation and a one-day field trip to the Marine Lab that included group discussions, lectures by scientists, and an artist-led art-making project creating foundobject collages to represent climate change processes. Students subsequently worked on small group activities to develop communication material for public visitors to the Marine Lab. We assessed both the learning activity and the communication products using pre- and post-field trip participant surveys, group discussions, and critiques of student products by communication experts from the University of Florida Cooperative Extension Program. Student surveys included questions about the impacts of climate change and level of scientific controversy surrounding climate change, a political as well as environmental topic in Florida (e.g., Carlton and Jacobson 2013). Student surveys were anonymous and matched for analysis using a numbering system.

Activities followed the 5E learning cycle (Bybee et al. 2006, Jacobson et al. 2015):

1. Engage-Learners are introduced to the task and make connections to things they already know. Motivating questions and problems are often used to spark curiosity and discussion.

An illustrated lecture and discussion by the Marine Lab biologist introduced students to the ecosystems of coastal Florida, climate change, and the needs for public communication materials for the Marine Lab.

2. Explore-Learners are directly involved in activities, field observations, data manipulation, etc. Questions and interaction with others help them build concepts about the new information.

On the field trip, the students visited Cedar Key Museum State Park to view traditional communication materials and then took a 45-minute boat ride along the coast to the Marine Lab. Students walked a loose transect from one side of the island to the other, and they were told to collect objects from around the area to be used later for an artist-led project making found-object collages. We showed students an example of a mixed media collage, entitled Mz 371 bacco, by the avant-garde German artist Kurt Schwitters, who hoped to "make connections, preferably between everything in the world" (MoMA 2015), to ensure all students began with a basic idea. This art form was selected for its inherently unbounded and nonrepresentational character. 


\section{Explain-Instructors provide information about the concepts through discussion, lecture, and readings.}

Both science and art instructors walked across Seahorse Key with the students. They answered questions about coastal ecology and climate change, as well as about collage making and creative idea finding. Students were encouraged to begin discussion of ideas about communication materials for Lab visitors. They were encouraged to do this creatively by trying to think of lots of ideas (fluency), using different types of materials or images (flexibility), in original ways (originality), some basic tenets of developing creative thinking skills (DeHaan 2011).

4. Elaborate-Learners apply these concepts in a new situation, testing patterns and ideas and verifying their understanding through assignments and activities.

Students gathered together around a large table and were provided with paper, paint, scissors, and glue. The assignment was explained in more detail as suggested by environmental artist Ilene Ray Sunshine (personal communication). Students were instructed to think about the tension of the process of climate change and represent it in a collage format. Students spent 2-3 hours creating collages and sharing materials and ideas. Afterwards, students described their thought processes while showing their individual collages and reflected on the experience. They also discussed ideas for the communication materials for Marine Lab visitors. Students were encouraged to brainstorm ideas, with the objective of promoting associative thinking through peer-peer learning (Johnson et al. 1994). Upon return to campus, students worked in small groups to subsequently develop the communication material about climate change for the Marine Lab's public visitors. This was a class assignment for the natural resource students, and the art students were invited to an internal critique of the penultimate products.

\section{Evaluate-Instructors employ assessment techniques to monitor and quantify learners' progress and provide feedback on program success.}

Our evaluation techniques used a formal knowledge test and an informal measurement based on observations of discussion groups and feedback from students and extension specialists. To evaluate the joint field trip activity, students completed pre- and post-field trip surveys. The surveys asked students to (a) describe the causes and potential impacts of climate change; (b) estimate the level of agreement among scientists about the causes of climate change, from $1=<10 \%$ level of agreement to $6=>91 \%$ agreement; and (c) list images they might use to communicate to Florida residents about the risks of climate change. Items a and $\mathrm{c}$ on the pre- and post-surveys were compared qualitatively, identifying general misperceptions and overall ideas. A paired ttest was used to compare mean responses to the level of scientific agreement queried in item $\mathrm{b}$. Students also participated in group discussions to reflect on changes in awareness about climate change, the development of communication materials, and influences on their creativity and experience. Two extension specialists, experts in public communication, provided critiques of the final communication products that students produced for the public visitors. These evaluations helped identify the potential influence the field trip experience had on students' learning and their ability to apply lessons learned.

\section{RESULTS}

\section{Changes in student awareness}

A comparison of the pre-post surveys demonstrated that after the field trip, descriptions of the causes and potential impacts of climate change in Florida became more detailed, with more correct components. Fewer misconceptions about weather and climate were evident after the field trip. Improvement in mean scores in knowledge about the extent that climate change is viewed as controversial among climate scientists was statistically significant. Among art class students, the pretrip average was 3.55 and the post-trip average was 4.55 (paired t-test, $\mathrm{t}=-.268, \mathrm{p}<$ $0.05)$. Among natural resources class students, the pretrip average was 4.4 , and the post-trip average was 5.22 (paired t-test, $t=-3.50$, $\mathrm{p}<0.05$ ). Based on the pre-post surveys, students in both classes provided a greater number of and more diverse ideas for images and illustrations to communicate about climate change after the field trip.

\section{Assessment of art-science experience}

Students provided positive feedback about both the field trip experience and the unique opportunity to integrate science and art students through the design of communication material that required exploration of an island and exploration of different perspectives. For example, a natural resource student noted: "One of the best aspects was to physically walk through the island with the art students; having a fluid discussion of the possibilities for developing public communication about the site from different perspectives was extremely beneficial. [The art students] look at the world in a whole different way." Another student wrote: "Engaging in the production of art was fun and creative. I could see nature in a different way and could interpret it differently for others." A third commented: "The artists really look at the world in a different way."

An art student wrote: "I had no idea climate change would have such an impact...really opened my eyes." Both science and art students noted that it was the most interesting activity in which they had participated among all their current courses. Student evaluations of the courses and faculty at the end of the semester were extremely high. The climate change art experience module was praised as fascinating and useful. Art students highly praised the instructor for providing the opportunity to visit a remote Marine Lab and interact with scientists.

The science students produced communication materials that included signs and a kiosk for the Marine Lab. An internal critique with the art students resulted in new layouts, reduced text, and attractive colors and images that included the use of cartoons. A final critique was conducted by extension specialists, who noted the originality and interest of the materials compared with class products in previous years. Improvements included more focus on visual impacts and creative captions using popular song titles and simple messages. The creative products were provided to the Marine Lab for public display. Resources were not available for further evaluation, but Marine Lab managers reported being very satisfied with the positive public response.

An unanticipated result was the continued effort by some students, even months after course completion, to send to the natural resource instructors unusual material about art and climate change, and to report an increased awareness of media 
coverage of climate issues as well as increased self-awareness related to their own environmental behavior.

\section{DISCUSSION}

Ideally, environmental education should promote interdisciplinary understanding of the natural and built environment through the sciences, arts, and humanities. However, educators focus on technical dissemination of scientific information (Turner and Freedman 2004), or other narrow disciplinary paradigms, which overlooks other ways of understanding the world. As students in natural resource and science fields explore action related to the challenges of mitigating or adapting to climate change and other environmental risks, it is critical that they understand how others view the world and different ways of communicating about it. Concomitantly, curricula for art students seldom include ecology and natural resource information, yet environmental art-making can address contemporary environmental and social issues, can promote systems thinking by recognizing interconnections and complexity (Rosenthal 2003), and often resonates with the public in emotional and intuitive ways.

Giannachi (2012) reviews ways in which artists have engaged the public in artwork addressing climate change through representation, performance, and actual mitigation. For example, environmental artist Eve Mosher designed participatory artwork, called HighWaterLine, in neighborhoods in New York City and Miami, USA, and Bristol, UK. Local artists attract the public to collaborate on drawing the high-water lines through their neighborhoods that are at high risk of flood damage due to sealevel rise, and social media helped carry the message to a broader community (Morris 2014).

Our integrated science and art project offered a way to make an emotional connection with students, stimulate new dialogues, and enhance more creative problem-solving approaches (Levinthal 1988). The comprehensive learning model of Illeris (2003) describes several types of processes, including assimilative learning, which happens when individuals add new information to previous mental structures, and accommodative learning, which happens when new information does not fit comfortably and old mental models must be restructured to accommodate the new information. Our joint field trip resulted in significant changes in knowledge about climate change among student participants, including their perceptions of its level of scientific controversy. Although complete accuracy was not achieved, many factors mitigate against this. Long-term media coverage of climate change has inflated the level of scientific controversy about climate change (Boykoff and Boykoff 2007), reflecting America's political divisions on the topic (Nisbet 2009). Only $35 \%$ of American teenagers and $39 \%$ of adults believe that most scientists think global warming is happening (Leiserowitz et al. 2011). In Florida, researchers found that policy makers did not perceive high risks from climate change (Carlton and Jacobson 2015), and University of Florida students revealed significant differences in perceptions of climate change based on their political affiliation (Carlton and Jacobson 2013). Perceptions of climate change risk are influenced by cultural cognition and group values, causing disagreement over even basic facts such as existence of scientific consensus (Kahan et al. 2011).

Illeris's (2003) third type of learning, transformative or expansive learning, occurs when an event is so powerful that restructuring happens in cognitive, emotional, and personality states. Although this profound change may be unrealistic to expect during a shortduration field trip (Jacobson 2009), in our study, incorporating artists and the arts into this activity helped engage multiple senses and emphasized social interaction, as well as providing support to participants. Including the production of art helped to make climate change impacts real and normalized what some students believed was a controversial scientific topic. The result was that students incorporated new and novel images in their products aimed at communicating about the impacts and conditions of mitigation and adaptation to climate change. Integrating science with the arts is an important yet ignored strategy for effective resource management and communication (Jacobson et al. 2007). Resource managers often make the mistake of designing communications that contain only factual information concerning the behavior they desire people to change, failing to consult the intended recipients of the message to identify which beliefs really influence how they behave in a particular situation (Ham and Krumpe 1996), what social norms dictate (McKenzieMohr and Smith 1999), or the range of incentives for behaving in certain ways (De Young 1993). This mistake has been particularly prevalent in climate change communication (Moser and Dilling 2011). Creating a learning environment that leads to a better understanding of different perspectives and backgrounds will help students improve their communication practices about important topics like climate change.

Spending time at a remote field laboratory with art and science students provided the opportunity for both ecological and artistic exploration of the island and informal, nonjudgmental conversations about climate change processes and what images might better convey information about them to the public. These types of informal field trip venues can help increase student interest and motivation (Behrendt and Franklin 2014). Our exploratory study did not directly measure changes in creativity at the individual level (e.g., using Torrance Tests of creativity, Lissitz and Willhoft 1985), but simply promoted the formation of novel ideas through associative thinking with students from diverse backgrounds and disciplines. This represents one strategy to nurture students' creative insights by promoting peer-peer learning across science and art disciplines (Gurnon et al. 2013).

Natural resource scientists currently bring a well-honed, disciplinary expertise to their endeavors to address climate change, but lack interdisciplinary knowledge and any understanding of the arts or other modes of viewing the world that could make them significantly more effective communicators. In this paper, we describe one technique to help train students to integrate creative thinking and the need for new approaches to communication and practice in resource management. Scholarship in climate change pedagogy requires such integration. Further research with an experimental design is needed to determine causative impacts of art-making and peerpeer learning for environmental topics. A recent review of biological field laboratories suggested that they can be used to span across the domains of traditional scientific disciplines (NRC 2014), but we feel this must be further expanded to include the arts and humanities, with the potential for more benefits by encouraging many ways of exploring and understanding the environment. 
Interdisciplinary instruction can be hampered by incentive and reward systems within academia that discourage collaboration (Derrick et al. 2014). More evidence-based work is needed to reduce barriers that often accompany the use of creative activities in university science and natural resource programs (Guevara 2002). Scientific disciplines have very different cultures, languages, and standards than the arts. We found that many aspects of planning, implementing, and evaluating our module faced challenges. The need to balance systematic procedures with spontaneity and quantitative accountability with subjective appraisal by the science versus art faculty created tension. The scientists had to modify their dependence on focusing on knowledge acquisition through lectures and demonstrations, while the artists had to modify their desire to simply "turn the students loose" for personal exploration. This tension was productive: "creativity and achievement often flourish in the presence of antagonists" (Derrick et al. 2012:8). One potentially related outcome in our study was that participating faculty received their highest student course evaluations. Rhoten (2003) found that the main barriers to interdisciplinarity was not from a lack of extrinsic attention or support at the top from administration, nor from a lack of intrinsic motivation by faculty and students at the bottom, but rather from a lack of systematic implementation in the middle. More resources are needed to promote systematic implementation, such as efforts to develop university management structures that support teacher development (Adams and Chisholm 1999) for cross-curricular innovation.

Responses to this article can be read online at: http://www.ecologyandsociety.org/issues/responses. php/8626

\section{Acknowledgments:}

We thank research assistants Beida Chen and Rebecca Soodeen. We are grateful to artist Ilene Sunshine for creative advice. We thank J. Hardesty and two anonymous reviewers for valuable review.

\section{LITERATURE CITED}

Adams, E., and T. Chisholm. 1999. Art, design and environment: a programme for teacher education. Journal of Art \& Design Education 18(3):337-334. http://dx.doi.org/10.1111/1468-5949.00191

Benuš, Š. 2010. Building interfaces between the humanities and cognitive sciences: the case of human speech. Arts and Humanities in Higher Education 9(3):353-374. http://dx.doi.org/10.1177/147$\underline{4022210363444}$

Berhendt, M., and T. Franklin. 2014. A review of research on school field trips and their value in education. International Journal of Environmental and Science Education 9:235-245.

Boykoff, M. T., and J. M. Boykoff. 2007. Climate change and journalistic norms: a case-study of US mass-media coverage. Geoforum 38:1190-1204. http://dx.doi.org/10.1016/j. geoforum.2007.01.008

Bybee, R. W., J. A. Taylor, A. Gardner, P. Van Scotter, J. C. Powell, A. Westbrook, and N. Landes. 2006. The BSCS 5 E instructional model: origins and effectiveness. Office of Science Education, National Institutes of Health, Bethesda, Maryland, USA. [online] URL: http://bscs.org/sites/default/files/ media/about/ downloads/BSCS_5E_Full_Report.pdf

Carlton, J. S., and S. K. Jacobson. 2013. Climate change and coastal environmental risk perceptions in Florida. Journal of Environmental Management 130:32-39. http://dx.doi.org/10.1016/ j.jenvman.2013.08.038

Carlton, J. S., and S. K. Jacobson. 2015. Using expert and nonexpert models of climate change to enhance communication. Environmental Communication 10(1):1-24. http://dx.doi. org/10.1080/17524032.2015.1016544

De Young, R. 1993. Changing behavior and making it stick: the conceptualization and management of conservation behavior. Environment and Behavior 25(3):485-505. http://dx.doi. org/10.1177/0013916593253003

DeHaan, R. L. 2011. Teaching creative science thinking. Science 334:1499-1500. http://dx.doi.org/10.1126/science.1207918

Derrick, E. G., H. J. Falk-Krzesinski, and M. R. Roberts, editors. 2012. Facilitating interdisciplinary research and education: a practical guide. American Association for the Advancement of Science, Washington, D.C., USA. [online] URL: http://www.aaas. org/report/facilitating-interdisciplinary-research-and-education-practicalguide

Donner, S. D. 2011. Making the climate a part of the human world. Bulletin of American Meteorological Society 92 (10):1297-1302. http://dx.doi.org/10.1175/2011bams3219.1

Ford Foundation. 2005. Annual report 2005. Ford Foundation, New York, New York, USA. [online] URL: https:// fordfoundcontent.blob.core.windows.net/media/1532/ar2005.pdf

Giannachi, G. 2012. Representing, performing and mitigating climate change in contemporary art practice. Leonardo 45 (2):124-131. http://dx.doi.org/10.1162/leon a 00278

Guevara, J. R. 2002. More than a 'bag of tricks:' using creative methodologies in environmental adult and community education. Adult Learning 13(2-3):24-29.

Gurevitz, R. 2000. Affective approaches to environmental education: going beyond the imagined worlds of childhood? Ethics, Place \& Environment 3:253-268. http://dx.doi. org/10.1080/713665905

Gurnon, D., J. Voss-Andreae, and J. Stanley. 2013. Integrating art and science in undergraduate education. PLoS Biology 11(2): e1001491. http://dx.doi.org/10.1371/journal.pbio.1001491

Ham, S. H., and E. E. Krumpe. 1996. Identifying audiences and messages for nonformal environmental education - a theoretical framework for interpreters. Journal of Interpretation Research 1:11-23.

Illeris, K. 2003. Towards a contemporary and comprehensive theory of learning. International Journal of Lifelong Education 22:396-406. http://dx.doi.org/10.1080/02601370304837

Intergovernmental Panel on Climate Change (IPCC). 2014. Climate change 2014: synthesis report. Contribution of working groups I, II and III to the Fifth Assessment Report of the 
Intergovernmental Panel on Climate Change (Core Writing Team, R. K. Pachauri and L. A. Meyer, editors). IPCC, Geneva, Switzerland.

Jacobson, S. K. 2009. Communication skills for conservation professionals. Second edition. Island Press, Washington, D.C., USA.

Jacobson, S. K., J. S. Carlton, and S. E. Cameron Devitt. 2012. Infusing the psychology of climate change into environmental curricula. Ecopsychology 4(2):94-101. http://dx.doi.org/10.1089/ eco.2012.0014

Jacobson, S. K., M. McDuff, and M. Monroe. 2015. Conservation education and outreach techniques. Second edition. Oxford University Press, Oxford, UK. http://dx.doi.org/10.1093/acprof: oso/9780198716686.001.0001

Jacobson, S. K., and M. D. McDuff. 1998. Training idiot savants: the lack of human dimensions in conservation biology. Conservation Biology 12(2):263-267.

Jacobson, S. K., M. D. McDuff, and M. C. Monroe. 2007. Promoting conservation through the arts: outreach for hearts and minds. Conservation Biology 21:7-10. http://dx.doi.org/10.1111/ j.1523-1739.2006.00596.x

Johnson, D. W., R. T. Johnson, and E. J. Holubec. 1994. The new circles of learning: cooperation in the classroom and school. Association for Supervision and Curriculum Development, Alexandria, Virginia, USA.

Kahan, D., H. Jenkins-Smith, and D. Braman. 2011. Cultural cognition of scientific consensus. Journal of Risk Research 14:147-174. http://dx.doi.org/10.1080/13669877.2010.511246

Kareiva, P., and M. Marvier. 2012. What is conservation science? BioScience 62(11):962-969. http://dx.doi.org/10.1525/bio.2012.62.11.5

Kleiman, P. 2011. Learning at the edge of chaos. AISHE-J: The All Ireland Journal of Teaching and Learning in Higher Education 3(2):62.1-62.11.

Leiserowitz, A., N. Smith, and J. R. Marlon, 2011. American teens' knowledge of climate change. Yale Project on Climate Change Communication, Yale University, New Haven, Connecticut, USA. [online] URL: http://environment.yale.edu/ climate-communication-OFF/files/American-Teens-Knowledgeof-Climate-Change.pdf

Levinthal, C. 1988. Messengers of paradise: opiates and the brain. Doubleday, New York, New York, USA.

Lissitz, R. W., and J. L. Willhoft. 1985. A methodological study of the Torrance Tests of creativity. Journal of Educational Measurement 22(1):1-11. http://dx.doi.org/10.1111/j.1745-3984.1985. $\underline{\mathrm{tb} 01044 . \mathrm{x}}$

McKenzie-Mohr, D., and D. Smith. 1999. Fostering sustainable behavior: an introduction to community-based social marketing. New Society Publishers, Gabriola Island, British Columbia, Canada.

Miles, M. 2010. Representing nature: art and climate change. Cultural Geographies 17(1):19-35. http://dx.doi.org/10.1177/147$\underline{4474009349997}$
MoMA. 2015. Kurt Schwitters. Merz Picture 32A. The Cherry Picture. [online] URL: http://www.moma.org/learn/moma_learning/ kurt-schwitters-merz-picture-32-a-the-cherry-picture-1921

Morris, S. 2014. Art project to highlight risk of climate change to Bristol. Guardian, 9 September. [online] URL: https://www. theguardian.com/environment/2014/sep/09/high-water-line-bristolclimate-change-risk-art-project

Moser, S. C., and L. Dilling. 2011. Communicating climate change: closing the science-action gap. Pages 161-176 in J. S. Dryzek, R. B. Norgaard, and D. Schlosberg, editors. The Oxford handbook of climate change and society. Oxford University Press, Oxford, UK. http://dx.doi.org/10.1093/oxfordhb/9780199566600.003.0011

Muir, M. J., and M. W. Schwartz. 2009. Academic research training for a nonacademic workplace: a case study of graduate student alumni who work in conservation. Conservation Biology 23(6):1357-1368. http://dx.doi.org/10.1111/j.1523-1739.2009.01325. $\underline{x}$

National Research Council (NRC). 2014. Enhancing the value and sustainability of field stations and marine laboratories in the $21^{\text {st }}$ century. National Academic Press, Washington, D.C., USA.

Nisbet, M. C. 2009. Communicating climate change: why frames matter for public engagement. Environment: Science and Policy for Sustainable Development 51:12-23. http://dx.doi.org/ doi:10.3200/ENVT.51.2.12-23

Rhoten, D. 2003. Interdisciplinary research: trend or transition. Items and Issues 5(1-2):6-11.

Rosenthal, A. T. 2003. Teaching systems thinking and practice through environmental art. Ethics \& the Environment 8 (1):153-168. http://dx.doi.org/10.1353/een.2003.0013

Rous, E. W. 2000. Literature and the land: reading and writing for environmental literacy. Heinemann, Boynton/Cook, Portsmouth, New Hampshire, USA.

Page 354 in S. K. Jacobson, M. D. McDuff, and M. C. Monroe, editors. 2006. Conservation education and outreach techniques. Oxford University Press, Oxford UK.

Scheffer, M., J. Bascompte, T. K. Bjordam, S. R. Carpenter, L. B. Clarke, C. Folke, P. Marquet, N. Mazzeo, M. Meerhoff, O. Sala, and F. R. Westley. 2015. Dual thinking for scientists. Ecology and Society 20(2):3. http://dx.doi.org/10.5751/es-07434-200203

Stankiewicz, M. A., and D. H. Krug. 1997. Art \& ecology. Art Education 50(6):4-5.

Turner, K., and B. Freedman. 2004. Music and environmental studies. Journal of Environmental Education 36:45-52. http://dx. doi.org/10.3200/JOEE.36.1.45-52

Weiss, R. P. 2000. The wave of the brain. Training and Development 7:20-23.

Wilson, E. O. 1998. Consilience: the unity of science. Knopf, New York, New York, USA. 